\title{
0 caso da gestão da reforma universitária brasileira: negociação como estratégia de ação política
}

\author{
Marco Aurélio Ruediger* \\ Vicente Riccio**
}

\section{Resumo}

Este artigo se baseia em dois relatórios elaborados por uma equipe da EBAPE/FGV, a partir das discussões mantidas durante os colóquios iniciais sobre a reforma universitária. Seu objetivo é possibilitar a compreensão do processo de reforma universitária em curso no país, pela análise do ponto de vista das entidades da sociedade civil participantes desses encontros. 0 artigo procura examinar a construção da lei , a partir dos elementos consensuais identificados nas discussões.

Palavras-chave: reforma universitária; gestão; legalidade; sociedade brasileira.

\begin{abstract}
This article is based on two Ebape/FGV reports on the issues discussed on the initial meetings about the universities system reform in Brazil. It tries to understand the ongoing process of universities system reform. Therefore, the paper tries to analyze civil society groups' perspectives on the issues discussed on the meetings. The article tries to understand the legal framework based on consensual elements identified in the meeting's discussion process.
\end{abstract}

Keywords: Universities system reform; management; legality; brazilian society.

\section{Introdução}

O objetivo do presente artigo é analisar, pelo ângulo da gestão das políticas públicas, a estratégia de negociação com representantes da sociedade civil adotada para a reforma universitária. Evidentemente, trata-se de uma experiência em construção, mas, de qualquer forma, já possibilita um aprendizado sistematizado sobre negociações complexas. Portanto, baseada nos colóquios iniciais da reforma, visa compreender de que maneira distintos atores sociais se posicionam em relação aos temas centrais do processo, tal como definidos pelo Poder Executivo, através do Ministério da Educação. O posicionamento das entidades da sociedade civil permite verificar de que maneira os princípios políticos são posicionados em espaços institucionalizados de debate.

O material empírico utilizado se fundamenta no material coletado pela observação dos autores nos encontros realizados nos dias 29-3, 30-3, 29-4 e 30-4 de 2004, ${ }^{1}$ que abordaram os seguintes temas:

- o papel da universidade;

- autonomia universitária;

- acesso e permanência no ensino superior;

- avaliação;

- financiamento;

- programas e conteúdos;

- gestão e estrutura.

" Professor da EBAPE e Coordenador do Mestrado em Administração Pública. Doutor em sociologia pelo luperj. E-mail: ruediger@ fgv.br.

** Professor da EBAPE. Doutor em sociologia pelo luperj. E-mail: vriccio@ fgv.br.

1 Além dos autores, os professores Maurício Motta e Márcio Carvalho participaram do processo de observação dos debates. Nesse sentido, somos gratos pelas observações realizadas pelos referidos professores.

Artigo recebido em junho de 2004 e aceito em julho de 2004. 
Esses tópicos serviram de base à discussão que será mapeada adiante, em termos de proximidade de concepções e de construção de consensos e dissensos. Contudo, é necessário ressaltar que foi abordado o ponto de vista das entidades em relação a princípios gerais, sua posição diante de princípios gerais e abertos que servirão de base para a futura regulação do sistema universitário, e não detalhes técnicos mais aprofundados.

\section{Princípios jurídicos abertos e política}

Um ponto importante a ser considerado no processo de reforma universitária é o objetivo de construir uma lei do ensino superior fundada na participação das entidades da sociedade civil. ${ }^{2}$ Como toda legislação contemporânea, a futura lei do ensino superior está assentada em princípios valorativos. Nos ordenamentos jurídicos contemporâneos, os princípios impõem a conformação da regra com a realidade social e a realização de objetivos político-sociais. A existência de tais instrumentos indica que uma "peculiaridade dessas prestações de índole positiva é a de que elas estão voltadas mais para a conformação do futuro do que para a preservação do status quo" (MENDES, 1999, p.47). Nesse sentido, a natureza dos princípios permite um espaço de discussão em que os aspectos políticos são assegurados, em virtude de suas características abertas.

Por outro lado, a constitucionalização de tais princípios está ligada à capacidade do ordenamento jurídico se adaptar às contingências sociais. Nonet e Selznick (1978), ao discutirem o tema do direito responsivo, afirmam que tal modelo está fundamentado numa perspectiva na qual o ordenamento jurídico esteja enraizado em seu contexto social, e na qual o interesse do Estado não é legitimado a priori. Tal discurso está ligado à perspectiva de gestão social - que mesmo com a crise dos sistemas de bem-estar, se mantém como um referencial moral -, na qual o "Estado assume a gestão que ele próprio cria, entre justiça social e igualdade formal" (SANTOS et al., 1997, p.25).

No caso dos primeiros debates a respeito da reforma universitária, o que se verifica é uma discussão acerca dos princípios norteadores da lei, cuja característica política é acentuada. Nesse contexto, a mediação realizada pelos atores permite de que forma se dá o seu posicionamento quanto aos núcleos "vertebradores" do sistema universitário brasileiro. É importante ressaltar que o processo desenvolvido é consultivo, tendo o ministério a prerrogativa de direcionar a ação administrativa.

\section{As discussões}

Com relação ao papel da universidade, a discussão aponta para a idéia de construção de um sistema universitário que permita superar uma concepção construída a partir do conjunto das Instituições Federais de Ensino Superior (Ifes). A tônica dos debates centrou-se no que seria o sistema universitário brasileiro, se baseado no modelo estatal ou caracterizado pela diversidade de instituições e configurações regionais. Nesse sentido, os atores caminham para um modelo marcado pela pluralidade e pela diversidade regional. Assim, a idéia de um sistema de ensino superior surge como o marco inicial para um processo de regulação caracterizado por grande legitimação social. Por outro lado, a clivagem público/privado aparece na discussão dos atores como um elemento central na distribuição dos recursos públicos e da capacidade de inserção no meio acadêmico. Isso é exemplificado no quadro 1 , levando em conta um eixo de grandeza fundado na intervenção estatal (-) menor ou (+) maior.

\footnotetext{
2 Participaram do primeiro colóquio, as seguintes entidades: Academia Brasileira de Ciências (ABC); Associação Brasileira das Universidades Comunitárias (Abruc); Associação Brasileira dos Reitores de Universidades Estaduais e Municípios (Abruem); Associação Nacional dos Centros Universitários (Anaceu); Associação Nacional das Faculdades Isoladas (Anafi); Associação Nacional das Faculdades e Instituições Superiores (Anafiso); Associação Nacional dos Docentes de Ensino Superior (Andes); Associação Nacional dos Dirigentes de Instituições Federais de Ensino Superior (Andifes); Associação Nacional das Escolas Técnicas e Tecnológicas (Anet); Associação Nacional de Universidade Particulares (Anup); Conselho Nacional de Educação (CNE); Confederação Nacional dos Trabalhadores em Educação (CNTE); Conselho Nacional dos Dirigentes dos Centros Federais de Educação Tecnológica (Concefet); Conselho Nacional de Secretários de Educação (Consed); Confederação Nacional dos Trabalhadores em Estabelecimentos de Ensino (Contee); Conselho de Reitores das Universidades Brasileiras (Crub); Federação de Sindicatos de Trabalhadores das Universidades Brasileiras (Fasubra); Fórum Nacional dos Conselhos Estaduais de Educação (FNCE); Sociedade Brasileira para o Progresso da Ciência (SBPC); Sindicato Nacional dos Servidores Federais da Educação Básica e Profissional (Sinasefe); União Nacional dos Dirigentes Municipais de Educação (Undime) e União Nacional dos Estudantes (UNE).
} 
Quadro 1

$(-)$

$(+)$

\begin{tabular}{ccc} 
Menor intervenção & Intervenção equilibrada & Maior intervenção \\
\hline Anup & Conseb & Fasubra \\
& Crub & Concefet \\
& Anaceu & Abruem \\
& Anafiso & UNE \\
& Abruc & Sinasefe \\
& SBPC & Contee \\
& FNCE & Undime \\
& & Andes \\
\hline
\end{tabular}

Embora os participantes tenham chegado a uma compreensão comum de que a expressão "universitário" não deve se limitar àqueles inseridos no sistema público federal, a perspectiva de manutenção do modelo atual é defendida com maior veemência pela Fasubra, Concefet, Abruem, UNE, Sinasefe, CONTEE, Undime e Andes. Outras instituições têm uma perspectiva do sistema centrado no ensino superior de natureza pública, mas organizado de maneira mais flexível. As instituições situadas nessa posição são: Conseb, Crub, Anaceu, Anafiso, Abruc, SBPC e FNCE.

Em outro extremo, isolada, está a Anup, que apenas sugere o controle das atividades da iniciativa privada dentro do marco regulatório já existente. A distinção entre público e privado é reafirmada na colocação a respeito da criação de secretarias distintas para essas instituições, no âmbito da Secretaria de Ensino Superior do Ministério da Educação (Sesu).

A idéia de universidade como instituição central no projeto de desenvolvimento nacional é outro elemento que surge nas discussões sobre o sistema de ensino superior no Brasil. Essa dimensão da universidade como parte de um projeto nacional é descrita no quadro 2, a partir de maior ou menor ênfase:

Quadro 2

$(-)$

$(+)$

\begin{tabular}{ccc} 
Menor ênfase & Enfase mediana & Maior ênfase \\
\hline Anaceu & Crub & $U N E$ \\
Anafiso & Concefet & Sinasefe \\
Consed & Fasubra & CONTEE \\
Anup & Abruc & ABL \\
FNCE & Abruem & Undime \\
& SBPC & \\
\hline
\end{tabular}

O tema da autonomia universitária envolve a polêmica sobre a natureza da autonomia e as formas de garantir seu exercício. Nesse ponto, verifica-se por parte de alguns setores, a sobreposição entre autonomia e financiamento estatal, sendo este um vetor imprescindível para a realização daquela. Dentro desse eixo temático, é possível organizar a disposição dos argumentos a partir de maior ou menor ênfase: 
Quadro 3

$(-)$

$(+)$

\begin{tabular}{ccc}
$\begin{array}{c}\text { Menor responsabilização } \\
\text { do Estado }\end{array}$ & Autonomia acadêmica & $\begin{array}{c}\text { Maior responsabilização } \\
\text { do Estado }\end{array}$ \\
\hline Anup & Abruc & UNE \\
& Anafiso & Abruem \\
Anet & Fasubra \\
Crub & Concefet \\
& FNCE & Consed \\
& SBPC & Andifes \\
& ABC & Andes \\
\hline
\end{tabular}

O tema do acesso e permanência apresenta duas vertentes importantes: a pedagógica e a socioeconômica. Quanto à primeira, os argumentos dos diversos atores ressaltam a necessidade de modificação dos ensinos fundamental e médio, assim como da estrutura curricular do ensino de nível superior. Com relação ao segundo problema, as posições tratam de políticas sociais destinadas a possibilitar condições efetivas de estudo aos setores mais carentes da sociedade. Parcela considerável das instituições ressaltou a necessidade de ampliação das vagas no sistema público. Uma das propostas levantada nos debates sugere a utilização dos recursos do Confat para o custeio de programas destinados à permanência do aluno carente na universidade e nos demais órgãos do sistema de ensino superior. O quadro 4 ilustra alguns pontos de vista:

Quadro 4

\begin{tabular}{ccc}
\hline $\begin{array}{c}\text { Ênfase no } \\
\text { sistema público }\end{array}$ & $\begin{array}{c}\text { Mudanças curriculares e políticas de } \\
\text { manutenção }\end{array}$ & $\begin{array}{c}\text { Ênfase no } \\
\text { profissional }\end{array}$ \\
\hline Andifes & ABC & SBPC \\
Andes & Consed & \\
& Anafi & \\
& Undime & \\
\hline
\end{tabular}

\section{0 segundo colóquio}

A segunda reunião ocorreu nos dias 29 e 30 de abril último, em Brasília, e nela se procurou mapear os argumentos das entidades ${ }^{3}$ representativas dos setores da educação superior e correlatos. Quatro eixos temáticos foram discutidos: avaliação, financiamento, programas e conteúdos, e gestão e estrutura. Do mesmo modo que no relatório anterior, busca-se, aqui, posicionar os atores em termos de proximidade de concepções, identificando os pontos de consenso e de dissenso, de maneira sistemática. Ao final, são estabelecidos alguns pontos norteadores para uma futura regulação jurídica do sistema de ensino superior brasileiro, como a garantia da qualidade do ensino, o reconhecimento da pluralidade das instituições e diversidades regionais, fundos públicos para financiamento da educação superior pública com controle social, mecanismos de incentivo à expansão com qualidade das instituições privadas e comunitárias, garantia de uma ordem pluralista de conhecimentos e um novo marco regulatório para a gestão e estruturação das instituições de ensino superior.

O tema da avaliação apresentou um significativo consenso entre os participantes, especialmente, quanto aos princípios norteadores do processo de avaliação. Os atores ressaltaram a necessidade de se construir um sistema marcado pela pluralidade, que reconheça as complexidades do sistema universitário brasileiro, e que seja marcado pelo diálogo e não por um caráter punitivo. Cabe ressaltar que para os presentes o conceito de

\footnotetext{
${ }^{3}$ Participaram do segundo colóquio as seguintes entidades: ABC, ABMES, Abruc, Anafi, Anet, Andifes, CNTE, Concefet, CONTEE, Consed, Crub, Fasubra, FNCE, Sinasefe, UNE.
} 
avaliação não deve se tornar um instrumento de distribuição de recursos escassos e aprofundamento das desigualdades regionais, mas deve se pautar pela construção de uma cultura democrática.

Além disso, a perspectiva democrática de avaliação não significa, no entendimento dos presentes, a inexistência de responsabilização dos atores. Ao contrário, ela é parte de um processo que se pretende formador e indutor de cidadania. Em alguns casos, a participação de elementos internos e externos à comunidade acadêmica é ressaltada pelos participantes. Há um grande consenso entre os atores com relação ao caráter sistêmico, plural, democrático e construtivo da avaliação. Algumas nuances podem ser verificadas no tocante ao Sistema Nacional de Avaliação da Educação Superior (Sinaes) (BRASIL, 2004), ${ }^{4}$ em que se sugere um aprimoramento desse sistema de avaliação. Assim, as entidades são agrupadas em função do destaque temático que seus representantes imprimiram às suas falas. Reafirma-se aqui o consenso dos atores em relação aos princípios norteadores do sistema de avaliação:

\section{Quadro 5}

\begin{tabular}{cc}
\hline Ênfase nos princípios do sistema de avaliação & Observação sobre o Sinaes \\
\hline ABC & ABMES \\
Consed & FNCE \\
Fasubra & CONTEE \\
CNTE & Anafi \\
CONTEE & Abruc \\
Sinasefe & \\
ANET & \\
UNE & \\
Crub & \\
Andifes & \\
Concefet & \\
\hline
\end{tabular}

Deve-se considerar que as observações a respeito do Sinaes são levantadas pelas instituições representantes do sistema privado e comunitário, como também pelos conselhos estaduais de educação e pelos representantes dos trabalhadores de estabelecimentos de ensino. Suas intervenções estão baseadas numa suposta inconstitucionalidade da legislação do Sinaes, que se caracterizaria por uma intervenção indevida do MEC no conselho das instituições de ensino.

O tema do financiamento mobiliza os atores principalmente na questão das instituições federais de ensino superior. Em razão de seu caráter público, a alocação de recursos estatais para o sistema assume caráter relevante na discussão sobre o financiamento. A necessidade de ações estatais direcionadas ao aluno carente também foi abordada pelas entidades, que consideram fundamental a existência de políticas públicas para a continuidade dos estudos desse expressivo grupo de estudantes. Algumas entidades, como a Anet, consideram tal tipo de iniciativa um financiamento destinado ao cidadão, e não à iniciativa privada. Em outro extremo, por exemplo, pode-se indicar a posição da Fasubra, que discorda de qualquer tipo de destinação de recursos públicos para entidades não-públicas, e que ainda sugere o fim das fundações de apoio nas universidades públicas brasileiras. Assim, os argumentos apresentados podem ser organizados em três grupos, o que é ilustrado pelo quadro 6:

1. predominância estatal estrita;

2. predominância pública articulada com outras variantes do sistema de ensino superior;

3. setor público combinado com sistema privado/comunitário.

\footnotetext{
${ }^{4}$ O Sinaes "é o novo instrumento de avaliação superior do MEC/Inep. Ele é formado por três componentes principais: a avaliação das instituições, dos cursos e do desempenho dos estudantes. O Sinaes avaliará todos os aspectos que giram em torno desses três eixos: o ensino, a pesquisa, a extensão, a responsabilidade social, o desempenho dos alunos, a gestão da instituição, o corpo docente, as instalações e vários outros aspectos".
} 


\begin{tabular}{ccc}
\multicolumn{3}{c}{ Quadro 6 } \\
\hline $\mathbf{1}$ & $\mathbf{2}$ & $\mathbf{3}$ \\
\hline Andifes & Concefet & Abruc \\
Fasubra & ABC & Anet \\
UNE & SBPC & Anafi \\
CNTE & FNCE & Anaceu \\
CONTEE & Consed & \\
\hline
\end{tabular}

O conteúdo dos programas indicou uma convergência de pontos de vista dos participantes quanto à necessidade de mudança nos currículos do sistema de ensino superior brasileiro e sua adequação às necessidades do mundo contemporâneo. Nesse sentido, o sistema brasileiro não tem sido eficiente. A proposta de adoção do ciclo básico é defendida por parcela considerável das entidades, e consubstanciada principalmente na posição da $\mathrm{ABC}$ e da SBPC. Essas entidades também ressaltam o modelo da conferência de Bolonha, que sugere três anos de formação básica, dois anos de formação profissional e três anos de pós-graduação. A SBPC sugere, ainda, o doutorado de três anos.

Outras entidades defendem o ciclo básico, sem aprofundar, no entanto, a proposta defendida pela ABC e pela SBPC. Por sua vez, a Anafiso critica a proposta de Bolonha, pois questiona se todos desejam possuir um mestrado acadêmico. Além disso, aponta o fato de tal perspectiva não contemplar adequadamente o problema dos tecnólogos. Assim, conforme o quadro 7, as opiniões das entidades podem ser representadas da seguinte forma:

1. ciclo básico + modelo 3, 2, 3;

2. ciclo básico sem advogar modelo 3, 2, 3;

3. mudança curricular sem adotar modelo ciclo básico;

4. reforma curricular a partir da educação básica.

Quadro 7

\begin{tabular}{cccc}
\hline 1 & 2 & 3 & 4 \\
\hline ABC & UNE & Anafiso & CNTE \\
SBPC & Concefet & FNCE & Abruc \\
& & Anet & Consed \\
& & Andifes & \\
& & Anafi & \\
\hline
\end{tabular}

O tema da gestão e estrutura está relacionado à democratização das instituições de ensino. Dentre os problemas especificados pelas entidades, está a questão dos orçamentos das universidades e a da participação da comunidade acadêmica na condução das instituições. Uma clivagem importante é a necessidade de um marco específico para as instituições públicas, privadas e comunitárias. Além disso, foi debatida a questão da representação e adoção de mecanismos paritários de representação. O quadro 8 esquematiza os argumentos expostos:

1. representação paritária dos segmentos;

2. representação paritária com peso maior dos docentes;

3. distinção entre o sistema público e privado;

4. existência de mecanismos democráticos. 


\begin{tabular}{cccc}
\multicolumn{4}{c}{ Quadro 8 } \\
\hline $\mathbf{1}$ & $\mathbf{2}$ & $\mathbf{3}$ & $\mathbf{4}$ \\
\hline UNE & UNE & SBPC & ABMES \\
SBPC & Concefet & FNCE & Abruc \\
CONTEE & & ANET & ABC \\
Fasubra & & Andifes & \\
Concefet & & Anafi & \\
& & Consed & \\
\hline
\end{tabular}

\section{Conclusão}

Os pontos de vista defendidos nos dois colóquios sobre a reforma universitária indicam as possibilidades de arranjos democráticos para o sistema universitário brasileiro. A construção desse sistema depende, em larga medida, de instituições democráticas capazes de sustentar um conjunto de instituições tão heterogêneas. Além disso, toda construção legal tem por característica alocar recursos escassos em função de um número grande de demandantes (PAULO, 2004).

A adoção de uma estratégia participativa, por sua vez, permite que os constrangimentos decorrentes da escassez de recursos não sejam eliminados, algo um tanto quanto improvável, mas mitigados. Nesse ponto verifica-se um potencial de construção institucional importante, pois apesar dos dissensos relativos à maior ou menor intervenção estatal no domínio universitário, ou da destinação das verbas públicas para entidades públicas ou privadas, dois elementos consensuais revelados no decorrer do debate têm grande potencial transformador:

- a idéia de um sistema de ensino superior plural e adequado às realidades regionais do país; e

- a adoção de políticas públicas para o ingresso e a manutenção dos alunos carentes nos cursos superiores.

Um exemplo interessante advém da construção do sistema anglo-americano de direito, que não é algo feito apenas pelo soberano, parlamento ou juízes, mas é a expressão de uma realidade maior, publicamente descoberta e declarada por eles. O sistema legal, antes de tudo, é um depositário dos valores historicamente construídos pela comunidade (POSTEMA, 1985). Essa construção enraizada nas comunidades locais sedimentou instituições como o júri, dotadas de capilaridade social (TOCQUEVILLE, 1981).

Por outro lado, o próprio sistema de valores e princípios construído a partir da tradição romana vem assistindo a uma "uma mudança drástica do código civil para a Constituição, do direito privado para o público, da corte comum para a constitucional, do positivismo legal para os princípios constitucionais" (MERRYMAN, 1985, p.148). Aqui, temos o ponto mais expressivo de contato entre as duas tradições. A base valorativa de uma sociedade fornece os elementos centrais de adequação das estratégias de estabilização, uma tarefa política e cotidiana.

Assim, os elementos consensuais identificados durante os colóquios revelam-se instrumentos de grande potencial democrático para a construção de uma legislação inovadora para o sistema de ensino superior brasileiro. Tal possibilidade, ainda não realizada, tem por característica a existência de um espaço de ação política que não seja marcado nem pelo corporativismo, nem pela obsessão cega pelo mercado. A demanda pela superação do déficit de cidadania no Brasil (CARVALHO, 2002) pode ofertar construções institucionais importantes, e o caso da educação adquire relevo em razão de seu potencial de superação de desigualdades.

De certo, essa "posição original concreta", aproveitando a deixa de Rawls (1997), pode vir a constituir um espaço importante no qual os atores envolvidos diante de diversas possibilidades, e cobertos por um "véu da ignorância", dispõem de elementos cognitivos suficientes para um retrato claro do futuro. A incerteza é a marca deste momento, podendo o arranjo ser mais favorável a uma ordem pública ou privada. No caso, existem decisões que levariam a um tipo de ordem cujo potencial máximo de ganho seria refreado a fim de se evitar 
uma perda maior. Assim, o esquema proposto procura compor os direitos e liberdades individuais e uma forma capaz de reduzir as desigualdades sociais, deixando de torná-las um ponto de desequilíbrio para a sociedade.

Esse dilema caracteriza o atual processo de reforma do ensino superior. Todavia, os dois elementos de consenso verificados nos debates, sistema plural e políticas inclusivas, constituem, como afirmado anteriormente, o material vivo para a gestão de um lei democrática e promotora da justiça social. 


\section{Referências bibliográficas}

BRASIL. Lei no 10.861, de 14 de abril de 2004. Cria o Sistema Nacional de Avaliação da Educação Superior (Sinaes). Disponível em: <http://www.inep.gov.br/superior/sinaes/>. Acesso em: 18-6-2004.

CARVALHO, M. A R. Cultura política, capital social, e a questão do déficit democrático no Brasil. In: Vianna, L. W. (Org.). A democracia e os três poderes no Brasil. Belo Horizonte: Editora da UFM G; Rio de Janeiro: Faperj, 2002.

MENDES, G. F. A doutrina constitucional e o controle de constitucionalidade como garantia da cidadania - necessidade de desenvolvimento de novas técnicas de decisão: possibilidade da declaração de inconstitucionalidade sem a pronúncia de nulidade no direito brasileiro. In: Mendes, G. F (Org.). Direitos fundamentais e controle de constitucionalidade. 2. ed. São Paulo: Celso Bastos, 1999.

MERRYM AN, J. H. The civil law tradition. Stanford: Stanford University Press, 1985.

NONET, P.; SELZNICK, P. Law and society in transition: towards responsive law. New York: Octagon Books, 1978.

PAULO, J. 0 dilema eficácia- eficiência da gestão pública. Revista Portuguesa e Brasileira de Gestão, v.2, n.4, p.30- 43, 2003.

POSTEMA, G. J. Bentham and the common law tradition. Clarendon: Oxford University Press, 1985.

RAWLS, J. A theory of Justice. Harvard: Harvard University Press, 1997.

SANTOS, B. S. et al. Os tribunais nas sociedades contemporâneas: o caso português. Porto: Edições Afrontamento, 1996.

TOCQUEVILLE, A.. De la démocratie en Amérique. Paris, Gallimard, 1981. 